\title{
PENGGUNAAN ZAT PENGATUR TUMBUH ROOTONE-F PADA STEK PUCUK MANGLID (Manglietia glauca BI)
}

\author{
(Application of Rootone-F Growth Regulator Substance \\ on Manglid Cutting (Manglietia glauca BI)) \\ Aris Sudomo ${ }^{1}$, Asep Rohandi ${ }^{1}$ dan/and Nina Mindawati ${ }^{2}$ \\ ${ }^{1}$ Balai Penelitian Teknologi Agroforestry \\ Jl. Raya Ciamis-Banjar Km 04, Po Box 5 Ciamis 46201. \\ ${ }^{2}$ Pusat Litbang Peningkatan Produktivitas Hutan \\ Jl. Gunung Batu Nomor 5 Bogor, Po Box 331 Telp (0251) 631238
}

Naskah masuk : 12 April 2012; Naskah diterima : 19 maret 2013

\begin{abstract}
Manglid (Manglietiaglauca BI) is the main tree species in West Java, Indonesia, due to its fast growing and multipurposes characteristics. Nevertheless, its seedling technique especially on the vegetative method is yet not available. This research is objected to find out the influence of six doses of Rootone-F hormone on survival and growth of cuttings of manglid seedling. The experiment applied Completely Random Design using 6 concentrations of Rootone-F growth regulator substance as treatment. The concentrations were 0, 50, 100, 200, and $500 \mathrm{ppm}$ respectively, as well as powder. The results proved that 100 ppm concentration produced the biggest amount of shoots (5 pcs/ $55 \%$ of improving), the longest root length ( $8.85 \mathrm{~cm} / 34.46 \%$ of improving) and the biggest amount of root (6.75 pcs/40.74 of improving). On survival percentage, the powder of Rootone-F produced the highest value (22.68\%), where as 100 ppm Rootone-F (20.68\%) showed not significant different on survival percentage as compared to control.
\end{abstract}

Keywords: Manglietia glauca BI, Rootone-F, cutting shoots

\begin{abstract}
ABSTRAK
Manglid (Manglietia glauca BI) merupakan tanaman andalan Jawa Barat, Indonesia, karena cepat tumbuh dan banyak kegunaannya, namun teknik pembibitan khususnya secara vegetatif belum dikuasai. Tujuan penelitian ini adalah mengetahui pengaruh 6 dosis hormon Rootone-F terhadap kemampuan hidup dan pertumbuhan stek pucuk manglid. Rancangan penelitian yang digunakan adalah Completely Randomized Design (CRD) dengan 6 perlakuan yaitu kontrol (tanpa hormon), Rootone-F 50 ppm, 100 ppm, 200 ppm, 500 ppm dan dioles. Hasil penelitian menunjukkan bahwa pemberian Rootone-F 100 ppm menghasilkan jumlah tunas tertinggi dibanding perlakuan lain (peningkatan $55 \%$ terhadap kontrol), panjang akar tertinggi sebesar $8,85 \mathrm{~cm}$ (peningkatan 34,46\% dibanding kontrol) dan jumlah akar terbanyak sebesar 6,75 buah (peningkatan 40,74\% dibanding kontrol). Pada parameter persentase hidup pemberian Rootone-F dioles menghasilkan nilai tertinggi yaitu $22,68 \%$ dan tidak berbeda nyata dengan pemberian Rootone-F 100 ppm (20,68\%).
\end{abstract}

Kata kunci : Manglietia glauca BI, Rootone-F, stek pucuk

\section{PENDAHULUAN}

Manglid (Manglietia glauca $\mathrm{BI})$ merupakan komoditas yang banyak ditanam petani hutan rakyat di Wilayah Priangan Timur seperti daerah Kecamatan Kawalu, Kabupaten Tasikmalaya, dan Kecamatan Panumbangan, Kabupaten Ciamis. Manglid sebagai jenis andalan setempat banyak disukai masyarakat di daerah tersebut karena jenis manglid relatif cepat tumbuh dan pemasaran produk kayu relatif mudah. Pohon manglid dapat tumbuh lurus dengan menyisakan sedikit tajuk aktif sehingga mempunyai nilai estetika yang indah dan berpotensi untuk sistem pola tanam agroforestry. Kayu manglid di wilayah Priangan timur banyak digunakan untuk pembuatan daun pintu, perkakas rumah tangga (almari, meja, kursi) dan bangunan rumah.

Selama ini masyarakat di Kecamatan Kawalu, Kabupaten Tasikmalaya, telah melakukan pembibitan manglid dengan biji dan telah menunjukkan prospek bisnis yang menjanjikan. Hal ini mendorong pengembangan manglid di hutan rakyat semakin meningkat. Potensi persebaran 
manglid di Jawa Barat cukup luas terutama di daerah-daerah pegunungan atau dataran dengan ketinggian berkisar diatas $500 \mathrm{~m}$ dpl. Habitat tanaman manglid kebanyakan mempunyai kondisi lingkungan yang relatif lembab, dingin dan bertanah liat (Sudomo, 2011).

Permasalahan yang ada dalam pengembangan jenis manglid adalah sifat benih yang rekalsitran sehingga benih tidak dapat disimpan lama. Oleh karena itu perbanyakan vegetatif jenis manglid sangat membantu dalam kegiatan penyediaan bibit yang berkualitas untuk penanaman sehingga tidak tergantung pada musim berbuah. Pembiakan vegetatif lebih unggul daripada generatif karena bibit hasil pengembangan secara vegetatif merupakan duplikat induknya karena mempunyai struktur genetik yang sama (Na'iem, 2000). Pembiakan vegetatif pada tanaman hutan diperlukan untuk konservasi genetik dan untuk meningkatkan tingkat ketelitian pada uji genetik dan non genetik (Campinhos, 1993, dalam Adinugraha et al., 2007). Keuntungan penggunaan bibit melaui pembiakan vegetatif adalah untuk memanfaatkan secepat mungkin keunggulan hasil pemuliaan yang diperoleh dari teknik seleksi dan persilangan (breeding) melalui pembangunan hutan klonal dan hutan famili (Nelson, 2003). Keuntungan lainnya adalah untuk pembangunan kebun benih klon, bank klon dan perbanyakan tanaman yang penting dari hasil kegiatan pemuliaan seperti hibrid yang steril atau tidak dapat berproduksi secara seksual serta perbanyakan masal tanaman terseleksi (Khan, 1993, dalam Adinugraha et al., 2007).

Untuk mempercepat keberhasilan teknik pembibitan melalui pembiakan secara vegetatif, perlu penggunaan zat pengatur tumbuh dalam membantu tumbuhnya perakaran. Penggunaan Rootone-F sebagai zat pengatur tumbuh tanaman selain harganya yang relatif lebih murah dibanding hormon IAA dan IBA, keberadaannya relatif mudah ditemukan di pasaran. Rootone-F terdiri atas senyawa-senyawa yang menjadi bahan aktifnya yaitu I-Naphtalene-Acetamide (NAD) 0,067\%, 2 Methyl-1- Naphtalene acetic acid (MNAA) 0,333\%, 3 Methyl-I Naphtalene acetamide (MNAD) 0,0135. Indole-3-butyric acid (IBA) $0,051 \%$ serta Tetranethyl-thiuram disulfide (Thiram 4\%). Rootone-F tidak digolongkan hormon tetapi lebih tepat sebagai zat pengatur tumbuh karena kandungan Thiram yang relatif tinggi dibandingkan dengan bahan aktif lainnya (Manurung, 1987, dalam Surata, 2008).

Belum diketahuinya teknik pembibitan vegetatif manglid tentunya dapat menjadi kendala dalam pembibitan, terutama jika akan melakukan pengembangan klon dan famili terseleksi. Stek pucuk merupakan salah satu cara alternatif potensial yang bisa dilakukan untuk pengembangan klon. Oleh karena itu dilakukan penelitian tentang teknik stek pucuk manglid (Manglietia glauca BI) sebagai antisipasi problem benih rekalsitran dan langkah awal pemuliaan tanaman manglid. Tujuan dari penelitian ini adalah mendapatkan teknik perbanyakan vegetatif manglid melalui stek pucuk dengan aplikasi hormon pertumbuhan Rootone-F.

\section{METODE PENELITIAN}

\section{A. Lokasi dan Waktu Penelitian}

Penelitian dilakukan di persemaian Balai Penelitian Kehutanan Ciamis pada Bulan Juni sampai dengan Oktober 2009. Pengambilan bahan tanaman dilakukan dari hutan rakyat manglid di Desa Pamalayan Kulon, Kecamatan Cijeunjing, Kabupaten Ciamis. Tanaman manglid tersebut ber-umur sekitar $\pm 1,5$ tahun ditanam dengan jarak tanam $2 \mathrm{~m} \times 3 \mathrm{~m}$.

\section{B. Bahan dan Alat}

Bahan yang digunakan dalam penelitian ini adalah tanaman manglid umur 1,5 tahun (bahan stek manglid), zat pengatur tumbuh (Rootone-F, aquades, pupuk organik jenis pupuk kandang, pasir, bambu, plastik sungkup, karung, polibag dan lain-lain. Sedangkan alat yang digunakan adalah ayakan, cangkul, gunting stek, gelas ukur, pisau cutter, cangkul, termohigro meter, oven, timbangan, kamera, sprayer, ice box, ember, meteran, kaliper, alat tulis dan lain-lain.

\section{Metode Penelitian}

\section{Pengambilan bahan stek}

Bahan stek pucuk manglid diambil dari pucukpucuk percabangan tanaman manglid berumur sekitar 1,5 tahun. Tanaman manglid ketika masih muda relatif banyak percabangan sehingga diperlukan intensif pruning. Cabang-cabang tanaman manglid hasil pruning tersebut yang digunakan untuk bahan stek pucuk manglid. Pengambilan bahan stek dilakukan pada sore hari sehingga relatif penguapan rendah dan telah terjadi fotosintesa.

Bagian pucuk dari percabangan tersebut diambil kemudian dipotong dengan panjang stek sekitar $8-12 \mathrm{~cm}$ dan setiap bahan stek pucuk me- 
nyisakan $2-3$ mata tunas dan $2-3$ daun seperti terlihat pada Gambar 1. Bagian pangkal di potong miring dengan gunting stek sehingga memberikan permukaan yang banyak untuk bersentuhan dengan media stek. Setiap daun di bahan stek dipotong sehingga tinggal menyisakan $1 / 3$ dari luasan daun. Hal ini berfungsi untuk mengurangi penguapan pada bahan stek pucuk ketika ditanam. Bahan stek yang telah dipotong dimasukkan dalam ember berisi air untuk menjaga kelembabannya.

\section{Pengemasan bahan stek}

Bahan stek bisa langsung ditanam apabila jarak antara lokasi pengambilan material stek dengan persemaian dekat. Apabila lokasi pengambilan bahan stek jauh maka bahan stek hasil pemotongan/pengguntingan dimasukkan dalam ice box (kotak es) yang berisi es batu kemudian dibawa ke persemaian.

\section{Penyiapan larutan zat pengatur tumbuh}

Zat pengatur tumbuh yang digunakan adalah

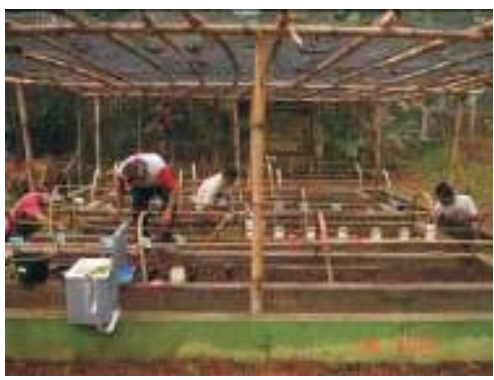

(a)

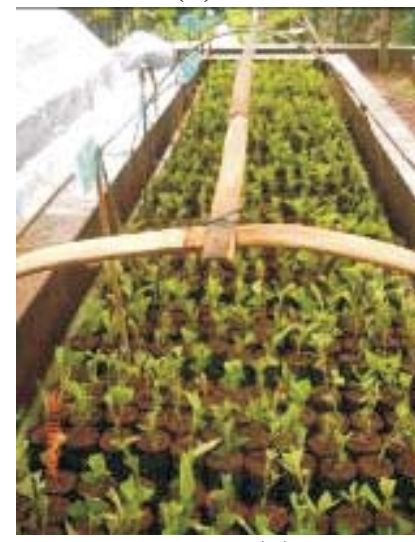

(c)

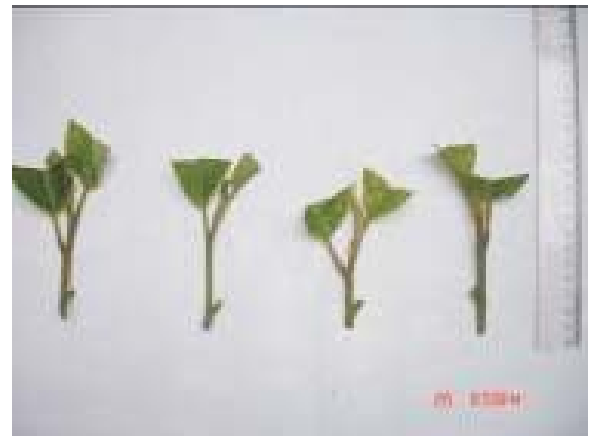

Gambar(Figure) 1. Metode pemotongan stek pucuk (Method of cutting tip shoots)

Rootone-F yang terdiri dari 6 konsentrasi ( 0 ppm, 50 ppm, 100 ppm, 200 ppm, 500 ppm dan Rootone-F dioles). Bahan stek dimasukkan dalam air sebelum ditanam. Setelah bahan stek dan larutan hormon tersedia sesuai dengan dosis perlakuan kemudian bahan stek dicelupkan ke dalam larutan tersebut selama beberapa menit (sekitar 15 menit) dan ditanam di media tanam.

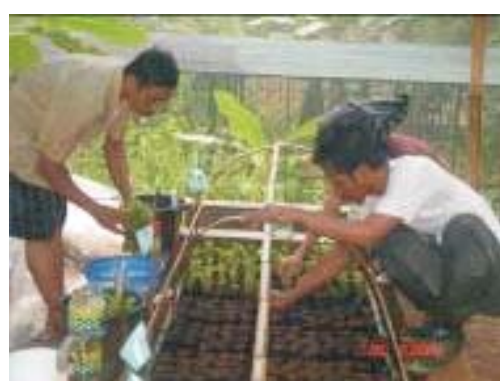

(b)

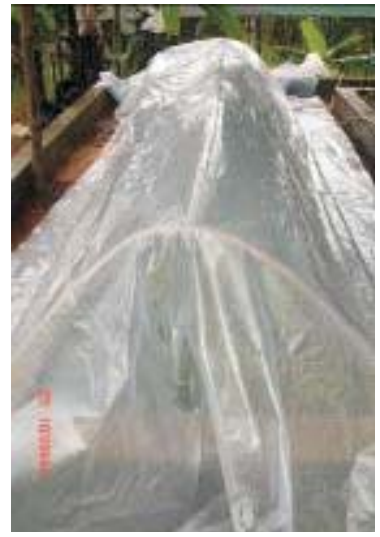

(d)

Keterangan (Remarks)

(a) Pemasangan perlakuan dan perendaman Rootone-F (Instalation of treatment and immersion of Rootone- $F$ )

(b) Pelubangan dan penanaman stek pucuk di polibag (Perforation and planting of cutting in polybag)

(c) Kerangka bambu untuk sungkup plastik (Bamboo framework for plastic lid)

(d) Pemasangan sungkup plastik (Fitting of plastic lid)

Gambar(Figure)2. Penanaman stek dan pemberian sungkup plastik (Planting and the provision of a plastic lid) 


\section{Penanaman dan pemeliharaan}

Bahan stek kemudian ditanam pada media pasir : pupuk kandang (1:1). Media pasir dan pupuk kandang terlebih dahulu dijemur di bawah terik matahari dengan meletakkannya di terpal atau alas karung plastik sekitar 3 hari. Penanaman di lakukan dengan melubangi media terlebih dahulu dengan ukuran kira-kira sebesar pensil dan kedalaman sekitar $2 \mathrm{~cm}$. Setelah itu, bahan stek dimasukkan pada lubang tanam dan diusahakan dapat tertutup oleh media. Kemudian dilakukan penyiraman untuk menjaga kelembaban media. Stek yang telah ditanam pada media di sungkup rapat dengan plastik tembus cahaya seperti pada Gambar 2. Penutupan sungkup dengan rapat mengakibatkan cahaya tidak masuk secara langsung, kelembaban dan suhu dalam sungkup tinggi. Pemeliharaan meliputi penyiraman secara rutin sekali sehari dan pembersihan rumput yang tumbuh di sekitar stek.

\section{Rancangan Percobaan}

Rancangan yang digunakan dalam penelitian ini adalah Rancangan acak lengkap (Completely Randomized Design, CRD). Perlakuan konsentrasi zat pengatur tumbuh (Rootone-F) yang digunakan yaitu kontrol (tanpa hormon), 50 ppm, 100 ppm, 200 ppm, 500 ppm dan dioles. Setiap perlakuan terdiri dari 3 ulangan dan pada setiap ulangan terdiri dari 50 stek. Parameter yang diamati dalam penelitian ini adalah persen hidup stek, jumlah tunas, jumlah total akar primer, panjang akar primer, berat kering akar dan berat kering daun stek.

\section{E. Analisis Data}

Data dianalisis menggunakan sidik ragam (Anova). Apabila hasil uji F yang dihasilkan dari analisis ragam berpengaruh nyata terhadap suatu parameter maka dilanjutkan dengan uji beda rata-rata Duncan (Sastrosupadi, 2000).

\section{HASIL DAN PEMBAHASAN}

\section{A. Hasil}

Hasil analisis keragaman menunjukkan bahwa pemberian zat pengatur tumbuh Rootone-F berpengaruh nyata terhadap persen hidup, jumlah tunas, jumlah akar dan berat kering daun, tetapi tidak berpengaruh nyata terhadap panjang akar dan berat kering akar stek sampai umur 3 bulan. Selanjutnya, untuk mengetahui beda rata-rata antar perlakuan dilakukan uji beda nyata terkecil Duncan yang selengkapnya disajikan pada Tabel 1.

Data pada Tabel 1 menunjukkan bahwa pemberian hormon Rootone-F dioles memberikan persen hidup tertinggi sebesar $22,68 \%$ dan berbeda nyata lebih tinggi dibanding kontrol. Data ini tidak berbeda nyata dengan perlakuan hormon Rootone-F 100 ppm yang menghasilkan persentase hidup sebesar 20,68\%. Secara keseluruhan, persentase hidup stek masih rendah yaitu dibawah $22,68 \%$.

Tabel(Table) 1. Pengaruh dosis Rootone-F terhadap kemampuan hidup dan pertumbuhan stek pucuk manglid umur 3 bulan (Effect of Rootone-F doses on survival and growth of manglid cutting at 3 months old)

\begin{tabular}{|c|c|c|c|c|c|c|c|}
\hline \multirow[b]{2}{*}{ No. } & \multirow[b]{2}{*}{$\begin{array}{l}\text { Dosis Rootone-F } \\
\text { (Doses of } \\
\text { Rootone-F) }\end{array}$} & \multicolumn{6}{|c|}{ Parameter } \\
\hline & & $\begin{array}{c}\text { Persen } \\
\text { hidup } \\
\text { (Survival) } \\
(\%)\end{array}$ & $\begin{array}{c}\text { Jumlah } \\
\text { tunas } \\
\text { (Number of } \\
\text { shoots) }\end{array}$ & $\begin{array}{l}\text { Panjang } \\
\text { akar } \\
\text { (Length of } \\
\text { root) }(\mathrm{cm})\end{array}$ & $\begin{array}{c}\text { Jumlah } \\
\text { akar } \\
\text { (Number of } \\
\text { roots) }\end{array}$ & $\begin{array}{l}\text { Berat kering } \\
\quad \text { akar } \\
\text { (Biomassa of } \\
\text { roots) (gram) }\end{array}$ & $\begin{array}{l}\text { Berat kering } \\
\quad \text { daun } \\
\text { (Biomassa of } \\
\text { leaves) (gram) }\end{array}$ \\
\hline 1. & $\begin{array}{c}\text { Kontrol } \\
\text { (Control) }\end{array}$ & $9,33 \mathrm{c}$ & $2,25 \mathrm{~b}$ & $5,80 \mathrm{a}$ & $4,00 \mathrm{~b}$ & $0,54 \mathrm{a}$ & $0,93 \mathrm{ab}$ \\
\hline 2. & $50 \mathrm{ppm}$ & $13,33 \mathrm{~b}$ & $2,50 \mathrm{~b}$ & $8,25 \mathrm{a}$ & $2,75 \mathrm{~b}$ & $0,10 \mathrm{a}$ & $0,53 b c$ \\
\hline 3. & 100 ppm & $20,68 \mathrm{a}$ & $5,00 \mathrm{a}$ & $8,85 \mathrm{a}$ & $6,75 \mathrm{a}$ & $0,38 \mathrm{a}$ & $1,27 \mathrm{a}$ \\
\hline 4. & $200 \mathrm{ppm}$ & $16,00 \mathrm{~b}$ & $3,50 \mathrm{~b}$ & $7,75 \mathrm{a}$ & $4,50 \mathrm{~b}$ & $0,14 \mathrm{a}$ & $0,35 \mathrm{c}$ \\
\hline 5. & $500 \mathrm{ppm}$ & $12,68 \mathrm{bc}$ & $2,00 \mathrm{~b}$ & $5,95 \mathrm{a}$ & $4,00 \mathrm{~b}$ & $0,38 \mathrm{a}$ & $0,81 \mathrm{bc}$ \\
\hline 6. & $\begin{array}{l}\text { Dioles } \\
\text { (Powder) }\end{array}$ & $22,68 \mathrm{a}$ & $2,25 \mathrm{~b}$ & $6,55 \mathrm{a}$ & $4,50 \mathrm{~b}$ & $0,40 \mathrm{a}$ & $0,66 \mathrm{bc}$ \\
\hline
\end{tabular}

Keterangan(Remarks) : Nilai yang diikuti dengan huruf yang sama dalam suatu kolom menunjukkan tidak berbeda nyata pada tingkat kepercayaan 95\% (Value followed by same letter on column indicated not different at 95\% level on Duncan Test) 


\section{B. Pembahasan}

Dari hasil penelitian terlihat bahwa penggunaan hormon Rootone-F dalam pembibitan stek pucuk manglid menghasilkan persentase hidup yang relatif rendah $(<22,68 \%)$. Rendahnya persentase hidup stek disebabkan oleh rendahnya kualitas bahan stek yang hanya diambil dari bagian pucuk percabangan tanaman manglid umur 1,5 tahun tanpa teknik juvenilisasi. Tanaman manglid sebagai bahan stek tersebut ditanam dengan jarak tanam $2 \times 3 \mathrm{~m}$ dan telah berketinggian sekitar 1,5 - $2 \mathrm{~m}$ dari permukaan tanah. Bahan stek yang berasal dari tajuk yang posisinya lebih atas kemampuan berakarnya lebih rendah (Menzies, 1992, dan Hartman et al., 1990). Bahan stek tersebut bersifat bukan tunas juvenil, tunas plagiotrof/bukan ototrof, tidak melalui teknik juvenilisasi melainkan dari pucuk percabangan tanaman manglid. Bahan stek yang berasal bukan dari tunas juvenil akan mempunyai kemampuan berakar dan tumbuh yang relatif rendah. Bahan stek pada tahap juvenil akan lebih mudah berakar dibandingkan dengan pada tahap dewasa (mature). Hasil penelitian Danu et al. (2011) menunjukkan bahwa bahan stek pucuk nyamplung (Calophyllum inophyllum L.) yang berasal dari anakan (seedling) menghasilkan persen hidup $(89,17 \%)$ terbaik dan berbeda nyata dibandingkan berasal dari pohon muda $(75,28 \%)$ dan pohon dewasa $(71,39 \%)$. Proses penuaan pohon dengan meningkatkan umur tanaman bisa menjadi hambatan penting dalam pembangunan hutan klonal. Pangkal pohon adalah bagian yang masih juvenil, kemudian semakin dewasa (mature) seiring dengan semakin tinggi posisinya dalam tajuk pohon (Hartman et al., 1990). Ketinggian bahan stek yang diambil dari tanaman dengan ketinggian sekitar 2 meter juga mempengaruhi kulitas bahan stek. Untuk ketinggian lebih dari $90 \mathrm{~cm}$ ada kecenderungan persen hidup dan panjang akar akan menurun (Pramono, 2008.).

Hartman dan Kester (1983) menyatakan bahwa banyak faktor yang mempengaruhi keberhasilan stek pucuk diantaranya pada saat pengambilan stek, umur pohon induk dan lingkungan tumbuh. Zat pengatur tumbuh Rootone-F yang diberikan pada tanaman ditujukan untuk merangsang keluar akar, jika diberikan pada tanaman yang terlalu tua hanya akan merangsang pembelahan sel yaitu yang ditandai oleh munculnya kalus pada luka bekas potongan. Pada kasus stump, kemungkinan lain dengan makin tuanya bahan stump akan terjadi proses pengayuan dan penebalan batang (Surata, 2008).

Teknik juvenilisasi pada tegakan dapat dilakukan dengan memotong bagian pucuk pohon/ topping dan memangkas percabangan sehingga menyisakan $1 / 4$ panjang cabang. Dari bagian pucuk pohon dan cabang yang dipotong ini akan muncul tunas-tunas juvenil baik arah ototrof maupun plagiotrof. Kemampuan menghasilkan tunas-tunas juvenil ini sangat dipengaruhi oleh umur tanaman, kondisi lingkungan (musim, cahaya, kesuburan tanah) dan karakateristik jenis pohon. Hacket (1988) menyebutkan bahwa satu cara untuk memperoleh bahan stek yang kembali juvenil sehingga potensi berakarnya tetap tinggi adalah dengan pemangkasan berat atau pembentukan kebun pangkas.

Pada kebun pangkas biasanya dilakukan pemangkasan untuk menumbuhkan tunas-tunas baru sebagai bahan stek pucuk. Dengan pembangunan kebun pangkas dapat diproduksi tunas juvenil yang relatif banyak dan mudah dalam pengambilannya. Kartiko et al. (2001) menjelaskan bahwa kesulitan untuk mendapatkan bahan stek bermutu dalam jumlah cukup dapat diatasi dengan membuat kebun pangkas yang relatif luas yang didukung dengan ruang pengakaran yang luas pula.

Selain itu, penyebab rendahnya persen jadi stek manglid juga disebabkan oleh timbulnya serangan jamur (kurang steril) yang cukup banyak sehingga menyebabkan kematian pada stek. Hal ini disebabkan oleh penambahan pupuk kandang pada media tanam dan proses sterilisasi yang kurang sempurna sehingga membuat media relatif kurang steril. Proses sterilisasi hanya dilakukan dengan penjemuran bahan media tanam (pupuk kandang + pasir) pada terik matahari selama 3 hari. Semestinya proses sterilisasi pada media dapat dilakukan dengan penggorengan atau pengovenan atau penjemuran dalam durasi waktu yang lebih lama serta pemberian benlate.

Penelitian Adinugraha et al. (2007) menunjukkan bahwa keberhasilan hidup stek pucuk Eucalyptus pellita F. Muell pada media pasir sungai sangat baik dibandingkan dengan media sabut dan campuran pasir dan sabut dengan kisaran persentase hidup 90-95\%. Dalam penelitian ini, penggunaan media pasir ditambah pupuk kandang bertujuan agar tidak ada proses penyapihan kembali setelah stek berakar karena telah tersedia unsur hara pada media tersebut. 
Lain halnya ketika hanya menggunakan pasir maka diperlukan penyapihan lagi pada stek yang telah berakar untuk dapat tumbuh besar, karena pasir merupakan media dengan porositas sangat baik tetapi miskin unsur hara. Stek pucuk pada media pasir memiliki kelembaban yang cukup dan stek yang ditanam dapat kokoh/tidak mudah goyah (Adinugraha et al., 2007).

Pemberian Rootone-F 100 ppm terhadap stek manglid memiliki jumlah tunas lebih tinggi dibanding perlakuan lain dengan peningkatan sebesar 55\% terhadap kontrol. Selain itu, pemberian hormon Rootone-F 100 ppm memberikan panjang akar tertinggi sebesar $8,85 \mathrm{~cm}$ (peningkatan $34,46 \%$ dibanding kontrol) dan jumlah akar sebanyak 6,75 buah (peningkatan 40,74\% dibanding kontrol). Peningkatan persen hidup karena dengan pemberian Rootone-F dapat mempercepat proses pertumbuhan akar sehingga meningkatkan pertumbuhan tunas. Hormon tumbuh dalam jumlah tertentu (optimal) akan aktif mengatur reaksi-reaksi metabolik penting dan salah satunya untuk memacu pertumbuhan akar.

Hal ini terlihat pada penelitian Surata (2008) bahwa Rootone-F 100 ppm sudah cukup baik untuk meningkatkan persen hidup stump Santalum album Linn. Hasil penelitian lainnya tentang penggunaan Rootone-F dosis 250 ppm berbentuk pasta pada Shorea selanica meningkatkan respon persen tumbuh stump secara maksimal (Hadengganan, 1984) dan selanjutnya Soedjoko (1983) melaporkan bahwa penggunaan Rootone-F dosis 100 ppm per cabutan pada bibit Shorea sp. meningkatkan respon persen tumbuh penanaman cabutan secara maksimal.

Penggunaan zat pengatur tumbuh (RootoneF) dengan konsentrasi rendah 100 ppm menghasilkan jumlah tunas, panjang akar dan jumlah akar yang lebih tinggi dibanding dengan konsentrasi lebih tinggi. Adinugraha et al., (2007), makin tinggi konsentrasi zat pengatur tumbuh yang digunakan, menghasilkan persentase bertunas dan berakar yang makin rendah. Menurut Surata (2008) pemberian Rootone-F di atas 120 ppm sudah menghambat pertumbuhan stump cendana, yang berarti bahwa zat pengatur tumbuh di atas dosis tersebut sudah terlalu tinggi dan melebihi dosis optimal bagi pertumbuhan stump cendana sehingga dapat merusak dan meracuni tanaman. Wareing dan Philips (1970) dalam Surata (2008) menyatakan bahwa auksin pada konsentrasi yang tepat sangat berperan dalam deferensiasi sel, namun pada konsentrasi di atas optimum dapat bersifat racun yang dapat menurunkan hasil yang diinginkan.

\section{KESIMPULAN}

\section{A. Kesimpulan}

Dari hasil dan pembahasan tersebut di atas dapat diambil beberapa kesimpulan sebagai berikut :

1. Pemberian Rootone-F 100 ppm memberikan pertumbuhan rata-rata jumlah tunas (5), panjang akar $(8,85 \mathrm{~cm})$ dan jumlah akar $(6,75$ buah) terbaik dan berbeda nyata dibanding perlakuan lain.

2. Pemberian Rootone-F 100 ppm menghasilkan persentase jadi stek pucuk $(20,68 \%)$ dan tidak berbeda nyata dengan Rootone-F dioles $(22,68 \%)$ tetapi keduanya berbedanyata lebih baik dibanding dosis Rootone-F lainnya.

\section{B. Saran}

1. Dalam pengadaan bibit manglid secara vegetatif disarankan dengan penggunaan RootoneF 100 ppm untuk menghasilkan pertumbuhan lebih baik.

2. Penggunaan metode stek pucuk dalam perbanyakan tanaman perlu dibarengi dengan teknik pembangunan kebun pangkas (teknik juvenilisasi) dan sumber bahan stek dari materi pemuliaan sehingga tercapai peningkatan produktivitas hutan tanaman, khususnya manglid.

\section{DAFTAR PUSTAKA}

Adinugraha, H.A., S. Pudjiono dan D. Yudistiro. 2007. Pertumbuhan Stek Pucuk dari Tunas Hasil Pemangkasan Semai Jenis Euchalyptus pellita F. Muell Di Persemaian. Jurnal Pemuliaan Tanaman Hutan Vol 1. No 1, Juli 2007. Balai Besar Penelitian Bioteknologi dan Pemuliaan Tanaman Hutan. Purwobinangun. Yogyakarta.

Danu, A. Subiakto dan A.Z. Abidin. 2011. Pengaruh Umur Pohon Induk terhadap Perakaran Stek Nyamplung (Calophllum inophyllum L.). Jurnal Hutan Tanaman Vol 8 No 1.2011. Bogor.

Hacket, W.P. 1988. Donor Plant Maturation and Adventitious Root Formation. In : Adventitious Root Formation in Cutting. T.D. Davis; B.E. Haissig and N. Sankhla eds. Discorides Prees. Oregon. 
Hadengganan, S. 1984. Penggunaan Hormone Rootone-F untuk Penanaman Stump Meranti (Shorea Selanica) di Kebun Percobaan Pusat litbang Hutan. Dermaga Bogor. Skripsi Sarjana. Fakultas Kehutanan. Institut Pertaniam Bogor. Bogor. Tidak diterbitkan.

Hartman, H.T. and D.E. Kester. 1983. Plant Propagation: Principles and Practise. Prentice Hall, Englewood Cliff. New Jersey. 727p

Hartman, H.T., D.E Kester and F.T. Davies Jr. 1990. Plant Propagation Principles and Practices. 5 th ed. Prentice Hall. Engle-wood cliffs. New Jersey 07632. P 221-223.

Kasno, S.P. dan Situmorang. 1973. Usaha-Usaha Mempercepat Pertumbuhan Akar pada Stek Coklat. KTP ke-IV. Budidaya Kopi dan Karet. Jilid 2. P :1-226.

Kartiko, H.D.P., Danu, W. Suwoyo dan P. Nugroho. 2001. Membuat Bibit Tanaman Langka : Ramin (Gonystylus bancanus) melalui Stek. Buletin Teknologi Perbenihan Vol. 8 No. 1, 2001. Balai Teknologi Perbenihan. Bogor.

Menzies, M.I. 1992. Management of Stock Plants for The production of Cutting Material. In Symposium" Mass Production Technology for Genetically Improved Fast Growing Porest Tree species. Bordeaux. France.

Na'iem, M. 2000. Prospek Perhutanan Klon Jati di Indonesia. Prosiding Seminar Nasional Status Silvikultur Di Indonesia Saat ini. Wanagama I. 1-2 Desember 2000. Fakultas Kehutanan. Universitas Gajah Mada. Yogyakarta.
Nelson, W. 2003. Propagation Plantation Trees from Cutting in Containers. 888. Management.Ltd. NewZeland.http;books.lulu.com/items/volum e_2/27000/2452/3/preview/Cutting Manual Evaluation. Copy. Pdf. Tanggal akses Desember 2011.

Pramono, A.A. 2008. Pengaruh Tinggi Pangkasan Pohon Induk dan Diameter Pucuk terhadap Perakaran Stek Benuang Bini. Jurnal Penelitian Hutan Tanaman. Vol 5 Suplemen No. 1. September 2008.

Santoso, J., Sulasmono., F. Rumawas dan N. Ninasari. 1993. Pengaruh Lama Etiolasi, Jumlah Ruas Bahan Stek dan IBA terhadap Pertumbuhan Stek Pucuk Kina Ledger (Chinchona ledgerina Moens) Klon Cib. 5. Buletin Penelitian Teh dan Kina $7(1 / 2): 39-50$.

Sastrosupadi, A. 2000. Rancangan Percobaan Praktis Bidang Pertanian. Kanisius. Yogyakarta.

Sudomo, 2011. Makalah Karakteristik Pertumbuhan dan Tempat Tumbuh Manglid di Desa Cikubang, Kecamatan Taraju, Kabupaten Tasikmalaya. Ciamis. Belum dipublikasikan.

Surata, I.K. 2008. Penggunaan Zat Pengatur Tumbuh Rootone-F pada Stump Cendana (Santalum album Linn). Jurnal Penelitian Hutan Tanaman. Vol 5 Suplemen No1, September 2008.

Soedjoko. 1983. Pengujian Penggunaan Hormon Rootone-F untuk merangsang Pertumbuhan Bibit Tusam (Pinus Merkusii dan Meranti (Shorea sp.) Skripsi Sarjana. Fakultas Kehutanan. Universitas Gajah Mada. Tidak dipublikasikan. 